\title{
Lares negros olhares negros: identidade e socialização em famílias negras e inter-raciais
}

\author{
Black home, black looks: Identity and socialization in black and inter-racial families
}

Angela Ernestina Cardoso de Brito*

\begin{abstract}
Resumo:
Este estudo visa a apreender como e em que circunstâncias famílias formadas por casais de diferentes origens étnico-raciais, sendo um negro e outro branco, preparam e/ou auxiliam seus filhos para enfrentar as discriminações que possam vir a sofrer em decorrência do racismo contra negros. Para tanto, foram entrevistados pais, mães e os filhos de duas famílias inter-raciais, perfazendo um total de sete entrevistas. Buscou-se aprofundar os conhecimentos sobre a socialização dos filhos mestiços, em famílias inter-raciais, a partir das falas do pai, da mãe e do próprio filho. Os dados obtidos e analisados permitem concluir que as famílias se valem de algumas estratégias para auxiliar os filhos a enfrentar o problema do racismo e da discriminação racial, apesar das dificuldades para elaborá-las, e que isto não constitui, pelo menos, aparentemente, prioridade na educação dos filhos. No entanto, pôde-se observar que há orientação para a construção do pertencimento racial e para os possíveis atos discriminatórios que os filhos poderão vir a sofrer. Desse modo, a orientação está associada a experiências discriminatórias vivenciadas pelos filhos, na família mais ampla, na escola, na rua, em clubes, mas se relaciona, também, a fortes laços afetivos.
\end{abstract}

Palavras Chave: Identidade; Socialização; Famílias negras; Famílias Inter-raciais; Serviço Social.

\begin{abstract}
:
This study aims at aprehending how and in what circumstances families formed by couples of different ethnic-racial origins, being one black and one white, prepare and/or assist their children to face the discrimination the might undergo in consequence of racism againt afro-americans. In oerder to achieve the goal, parents and children of two interracial families were interviewed, in a total of seven interviews. We tried to deepen the knowledge on socilization of mixed off springs within interracial families, from the statements of the parents and the child. The data obtained and analyzed allow us to conclude that the families use up some strategies to assist their children in facing the problem of racism and racial discrimination, even though there are difficulties in elaborating them, and they do not constitute, at least apparently, a priority in children education. However, it was possible to observe that there is a construction of racial belonging, and orientation on possible discriminatory acts kids may undergo. Thus, the orientation is associated
\end{abstract}

\footnotetext{
* Assistente Social graduada pela Universidade Estadual Paulista Júlio de Mesquita Filho-UNESP, mestre em Metodologia da Educação pela Universidade Federal de São Carlos-UFSCar, doutoranda em Política Social pela Universidade Federal Fluminense - UFF e professora do Curso de Serviço Social na Universidade Estadual de Montes Claros/MG-Unimontes. Financiamento: CAPES e Ford Foundation. E-mail: angelafro@yahoo.com.br
} 
to discriminatory experiences lived by the children within the expanded family, at school, on the street, in clubs, being attached to strong affective bonds.

Keywords: Identity. Socialization. Black families. Interracial families. Social work.

\section{Introdução}

A tentativa de compreender os fatores que colaboraram na educação de filhos de negros e brancos, interferindo em suas experiências compartilhadas com outras pessoas e na forma de se posicionarem diante dos problemas raciais na sociedade, suscitou a necessidade de se estudar o processo de socialização dessas famílias. Adotou-se, assim, uma perspectiva que permitisse compreendê-las para além do aspecto social, o que implicou apreender como e de quê maneira experiências, crenças e tradições compartilhadas pelos membros da família inter-racial, pelos mestiços, são representadas, produzem e se reproduzem, nas estruturas de poder, nas instituições sociais e nos sistemas de significação do próprio mestiço.

Silva (1998) aponta que é nas relações e nos processos de compartilhamento entre as pessoas e os grupos que reside a capacidade mantenedora ou transformadora das estruturas sociais. Portanto, ao se investigar a socialização de famílias inter-raciais, não se pretende desconectá-las dos conflitos e das condições de alienação e dominação a que foram submetidas ao longo das décadas. Pretende-se, outrossim, investigar a maneira pela qual pais e mães brancos/as e negras/os e seus filhos têm se colocado em relação a essas condições de dominação. A intenção é examinar como resistem, o que pensam, o que dizem e como travam o embate contra a discriminação. Nesse sentido, segundo Silva:

\footnotetext{
Torna-se imperioso reescrever os conhecimentos, a partir da perspectiva de cada um dos grupos étnicos que constituem a nação. Assim conhecerão uns aos outros nas suas diferenças, não ficando a maioria instada a abandonar as suas raízes culturais mais fecundas e assumir uma outra que lhe é alheia (SILVA, 1998, p.254).
}

Assim, é necessário entender os acontecimentos históricos e os diferentes pontos de vista de cada sujeito que constitui a família negra e inter-racial. Desse modo, é fundamental conhecer a articulação e a reprodução que acontece no interior, no exterior e na interconexão dos diferentes grupos e processos sociais, que fica evidente nas falas 
transcritas neste estudo. Essas falas, que desvendam a maneira de ver o mundo, de abordá-lo e de recriá-lo, tornam possível a identificação da perspectiva do pai negro e branco, da mãe negra e branca e também a do mestiço sobre a questão das diferenças raciais e dos diferentes modos de viver e de educar, peculiares a cada família e a cada grupo de cada indivíduo. Buscou-se enfatizar, assim, o significado, o sentido e o efeito que essa educação produz na construção do mestiço e, sobretudo, os critérios ou parâmetros que são acionados para determinar essa construção.

Diante disso, considerando-se que a aprendizagem do racismo começa desde cedo e inclui familiares, amigos, igreja, escola, clube, e que o racismo e seus derivados estão presentes na sociedade brasileira, destaca-se a carência dos estudos em relação à socialização em famílias negras. Enfatiza-se, ainda, a completa ausência de estudos referentes a famílias inter-raciais, uma vez que as pesquisas existentes, em sua maioria, abordam a socialização de modo amplo, sem focalizar o pertencimento racial, o que resulta em uma enorme lacuna teórica.

\section{Parâmetros para compreensão das redes de socialização}

Por conta da necessidade de se estudar as particularidades, o envolvimento e a interação dos componentes dessas famílias com eles mesmos e com outras pessoas que perfazem as redes de relações familiares, é fundamental se reportar à família, pois, nas sociedades ocidentais, é tarefa desta a introdução dos indivíduos "no mundo objetivo de uma sociedade" (BERGER; LUCKMANN, 1976). A família aparece como espaço privilegiado das relações mais íntimas e é essencial para a construção da identidade pessoal (BERGER; LUCKMANN, 1976; GOMES, 1987; SILVA, 1987). Ainda de acordo com Berger e Luckmann (1976), no seio da família, o novo membro da sociedade interioriza um mundo já posto e significado, que the é apresentado de forma pré-definida, ou seja, construído anteriormente à sua existência.

De forma bastante simplificada, entende-se que a família, desde a origem da humanidade, passou por inúmeras transformações, seja em sua composição, em sua função, em suas delimitações classificatórias ou em suas formas. Entretanto, apesar das inúmeras modificações que a família sofreu e ainda vem sofrendo, para muitos, continua tendo uma importância fundamental no processo educativo dos filhos. 
Vista como primeiro grupo de socialização, a família é atravessada, inteiramente, pela dimensão política, além disso, é concebida como lugar para o exercício da cidadania. É nela que também se dá a apreensão de direitos e deveres, o que implica no desenvolvimento de práticas de tolerância, de divisão de responsabilidades, de busca coletiva de estratégias de sobrevivência, de laços de solidariedade e apreensão de valores culturais etc.

Embora a família, de modo geral, seja entendida como um dos principais espaços socializadores, o que ficou evidente nas falas dos entrevistados durante a pesquisa, neste trabalho, foi desconsiderada qualquer visão normativa e dogmática dessa instituição, compreendendo-se que não existe família num sentindo único e específico, fixo e imutável, mas sim várias combinações de sentidos e significados circunscritos histórica e socialmente. ${ }^{1}$

Compreende-se, aqui, a família a partir da moderna historiografia, isto é, como uma instituição social básica, histórica, que se transforma sincrônica e diacronicamente. Dessa maneira, desconsidera-se a ideia de um padrão único de organização familiar, de um modelo, mesmo que as duas famílias participantes dessa pesquisa sejam compostas por pai, mãe e filhos, cuja estrutura, aliás, não resultou de escolha intencional.

Como há poucos trabalhos que discorrem sobre a socialização de famílias negras e famílias inter-raciais, partiu-se, inicialmente e contraditoriamente, para uma análise dos conceitos utilizados por Berger e Luckman (1976). Inicialmente, porque esses dois autores foram os primeiros a estudar a construção do sujeito e sua interação com o mundo. Contraditoriamente, porque discorreram precisamente sobre o conceito de socialização, do ponto de vista, exclusivamente, de famílias brancas. Entretanto, desconsideram, em seu debate, o recorte e a especificidade de famílias negras e inter-raciais. Por isso, de seu trabalho, foram considerados alguns pontos, aqueles que ajudam a situar o estudo em questão. Berger e Luckman (1976), sobre a construção do sujeito em sua interação com o mundo, definiram um modelo conceitual para a interiorização da realidade e diferenciaram dois processos básicos de socialização: o da socialização primária e o da

\footnotetext{
${ }^{1}$ A afirmação a seguir, ilustrando nossa forma de abordagem: "Antes de julgar ou desejar encaixar as pessoas em modelos preestabelecidos, é necessário ter-se clareza dos próprios conceitos e preconceitos em relação ao tema. Uns e outros estão carregados de crenças e valores que influenciam nossos sentimentos e orientam nossas ações." (SZYMANSKI, 2001, p. 8).
} 
socialização secundária. Este estudo enfatiza a importância de uma reflexão sobre a socialização e o socializar-se, classificados pelos autores como socialização primária, quer na perspectiva individual, quer na perspectiva social ou racial, pois as experiências compartilhadas com outros grupos, outras pessoas, na primeira socialização, assumiram papel relevante na trajetória de vida das pessoas entrevistadas nessa pesquisa.

A socialização, nos termos que a conceituam Berger e Luckman (1976), é um processo de construção social do homem. Dentre as modalidades de socialização, neste estudo, abordou-se, principalmente, da socialização primária - processo realizado basicamente pela família, que ocorre desde o nascimento do indivíduo e, por isso, sem que Ihe seja possível escolher as fontes socializadoras. Assim, na fase de socialização primária, o indivíduo permanece restrito a aprender o que the é ensinado quase que, unicamente, pelos mais próximos, sobre a sociedade e a cultura.

A socialização primária possibilita ao indivíduo tornar-se um membro da sociedade. A socialização secundária é subsequente ao processo de socialização primária, e podem ocorrer vários processos de socialização secundária, dependendo da variedade de instituições sociais ligadas ao sujeito ao longo de sua vida. Por meio dessas instituições, o indivíduo integra-se, paulatinamente, a um gênero, a uma classe, a u m bairro, a uma religião, a um país.

A partir da importância da socialização primária, é importante enfatizar a maneira como os elementos socializadores primários se comportam frente ao processo de socialização secundária, no que diz respeito à preparação para o trabalho e, portanto, para a necessária e inevitável distribuição social do conhecimento. Ela, desta forma, consiste em todo processo de inserção do homem, já socializado, em novos setores institucionais (GOMES, 1994). A socialização primária não se constitui apenas como aprendizado cognitivo, pois

[Ela] Ocorre em circunstâncias carregadas de alto grau de emoção [...] A criança se identifica com os outros significativos por uma multiplicidade de modos emocionais. Quaisquer que sejam, a interiorização só se realiza quando há identificação. A criança absorve os papéis e as atitudes dos outros significativos, isto é, interioriza-os tornando-os seus (BERGER; LUCKMANN, 1976, p. 176). 
Nesse processo, a apreensão do mundo ocorre quando o socializado se identifica com os mediadores: pais ou responsáveis. Isso faz com que a socialização primária aconteça num contexto de fortes laços afetivos. Como resultado, ao interagir com os outros, a criança aprenderá os hábitos, usos, costumes, atitudes, opiniões e valores predominantes na sociedade ampla e, especialmente, no espaço de inserção de seu grupo social. Esta constitui uma relação dialética por meio da qual o indivíduo internaliza o mundo e, ao mesmo tempo, pode agir para transformar e intervir no seu meio. A criança torna-se um parceiro ativo e, consequentemente, suas ações, atitudes e comportamentos sociais não serão meras reproduções das atitudes de seus mediadores; pouco a pouco, a criança pode buscar novas informações em outros lugares, além do espaço familiar (BERGER; LUCKMANN, 1976).

Como já visto, a socialização primária ocorre num contexto de fortes laços afetivos, motivo pelo qual o mundo internalizado, no decorrer do processo, se torna muito mais persistente e resistente à erradicação do que outras internalizações ocorridas posteriormente (BERGER; LUCKMANN, 1976). Assim, a família pode ser entendida como a unidade subcultural que prepara a criança para atuar em seu meio e em sua cultura. Nesse contexto, Erikson (1976) considera de extrema importância o relacionamento da mãe com a criança e aponta importantes fatores para que o resultado da socialização lhe seja favorável ou não: o clima emocional da família, o formato familiar, a situação econômica, os tipos de relações entre pais e filhos, além dos métodos de socialização adotados.

Esse processo induz a um repensar sobre as implicações teóricas acerca da socialização primária, já que não se deve deixar de considerar que é, cada vez mais precoce, a introdução da criança em outras agências socializadoras, tais como a escola, os internatos e os berçários. Há os casos em que ocorrem abandono e isolamento, quando não existe qualquer relacionamento estável ou fixo voltado aos cuidados da criança. Deve-se levar em conta, ainda, os próprios relatos dos participantes da pesquisa, que consideram importante não somente a família, a mãe e outros membros, mas outras instituições, como a escola, a rua, os clubes, que influenciam, fortemente, dois processos: o educativo e o de formação da identidade. ${ }^{2}$

\footnotetext{
${ }^{2}$ No Brasil, muito se fala sobre a identidade negra, mas quase não se ouve um discurso ideológico articulado sobre a identidade "amarela" e a identidade "branca", justamente porque os que, coletivamente, são
} 
Berger e Luckmann (1976) consideram a socialização como um processo compulsório, aplicado a todas as pessoas, portanto, sem distinção de raça. O processo de socialização ocorre diferentemente entre os diversos grupos étnico-raciais e tem suas peculiaridades quando entra em cena a questão racial, ou melhor dizendo, relações entre diferentes grupos raciais, informadas pela ideologia do racismo. A socialização deve ser entendida como um processo de construção de conhecimento da sociedade, no qual todos os saberes dão suporte para o indivíduo se relacionar com a sociedade e, a partir daí, nela se situar ${ }^{3}$.

$\mathrm{Na}$ família, como em qualquer outro grupo social, grande ou pequeno, desenvolvem-se padrões, e cada indivíduo passa a ter uma relação diferente com os outros, conforme posições hierárquicas, tais como raça, grupo social, nacionalidade e afiliação étnica. Isto significa que a criança incorpora determinadas normas e valores e acaba por se identificar com um grupo particular, diversificado em relação a outros, mas aprende a se relacionar com outros.

Cabe destacar que alguns padrões de comportamento apreendidos pelas crianças embutem características da cultura e do meio em que ela se encontra, ao passo que outros são peculiares à própria família. A criança aprende valores, sentimentos e expectativas de posição, por intermédio de cada membro de sua família e de outras pessoas com que convive. É preciso considerar que a família exerce, desde muito cedo, grande influência na transmissão de valores e crenças a respeito dos grupos raciais.

Para Bloom (1974), o desenvolvimento da "consciência do eu" tem como prérequisito a figura do adulto. O autor entende, ainda, que a consciência racial, na socialização primária, desenvolve-se alicerçada no conteúdo das experiências filtradas pelos componentes do núcleo familiar da criança. Pode-se dizer, assim, que a subjetividade do adulto, responsável pela socialização da criança, torna-se

portadores das cores de pele branca e amarela não passaram por uma história semelhante à dos brasileiros coletivamente portadores da pigmentação escura (MUNANGA, 1999). Os negros foram e são objeto de representações negativas e de construção de uma identidade negativa que, embora, inicialmente, apenas atribuída, acabou sendo interiorizada e naturalizada pelas próprias vítimas da discriminação racial.

${ }^{3}$ A família, por sua vez, também deve se preocupar em como a instituição escolar, por meio do relacionamento aluno/aluno e professor/aluno, reproduz ou não o esquema estrutural que é binário, que lida com a oposição negro/branco, criança/adulto, bom/ruim, na sociedade. Seus agentes, sobretudo os professores, podem contribuir, consciente ou inconscientemente, para a formação das identidades das crianças negras e mestiças, e isso de forma positiva ou negativa e inferiorizada, o que pode promover a autorejeição e a autodepreciação desses indivíduos. 
subjetivamente significativa para ela. Nesse sentido, Barbosa (1987) e Souza (1999) destacam que os familiares, muitas vezes, reforçam normas e monitoram comportamentos em relação aos grupos. Dessa maneira, na socialização primária, por meio das relações sociais, a criança pode ser induzida a sedimentar sentimentos racistas, além de incorporar um modo de pensar negativo em relação a determinados grupos raciais.

Quando se aponta a indução da criança pelo adulto, tenciona-se relacioná-la ao fato de, nessa fase, o adulto ser o mediador entre o mundo e a criança. Não é necessário, portanto, realizar qualquer pronunciamento verbal, explícito, à criança, a respeito da importância social da cor da pele, pois a atribuição do significado social às propriedades físicas, entre outros atributos, é consequência da compreensão sucessiva que ela vai adquirindo ao se confrontar com sinais de aceitação ou rejeição, implícitos nas atitudes e nas condutas dos membros de seu primeiro grupo de referência. A descoberta das qualidades e atributos físicos influencia o processo de identidade pessoal, além de servir de base para a busca do reconhecimento social. Conforme Bloom (1974), é a partir da infância que a criança vai percebendo o baixo prestígio que ela e seu grupo de referência possuem na esfera da vida social.

Silva (1987), em uma pesquisa realizada com trabalhadores rurais negros, em Limoeiro, Rio Grande do Sul, mostrou que a espacialidade está engajada na construção do mundo, e aí é que se encontram as raízes da identidade4; já em outro momento, a mesma autora afirma o seguinte:

\begin{abstract}
No encadeamento de ações que constituem as experiências vividas, as pessoas vão construindo sua espacialidade. Isto é, seus espaços de atuação. Parentes, companheiros, circunstâncias de vida, localidades como a comunidade, a vizinhança, o bairro, locais, como a escola, a igreja, o terreiro de religião, o centro comunitário, o trabalho são como que pontos interligados que oferecem referência para a construção daqueles espaços (SILVA, 1998, p. 389).
\end{abstract}

\footnotetext{
${ }^{4}$ Vista do ponto de vista histórico, a identidade negra não surge da tomada de consciência de uma diferença de pigmentação ou de uma diferença biológica entre populações negras e brancas e/ou negras e amarelas. A identidade negra surge de um longo processo histórico que começa com o descobrimento, no século XV, do continente africano e de seus habitantes pelos navegadores portugueses. Este descobrimento abriu $\mathrm{O}$ caminho para o desenvolvimento de relações mercantilistas entre a Europa e a África para o tráfico negreiro, a escravidão e, enfim, para a colonização do continente africano e de seus povos (MUNANGA, 1999).
} 
Embora creches, pré-escolas e muitas outras instituições voltadas ao atendimento das crianças também promovam a socialização primária, de maneira auxiliar e complementar à da família, algumas famílias, muitas vezes, permanecem como o agente socializador mais importante, pelo fato de constituírem o gruo mais próximo, emocional e fisicamente. Dessa maneira, outras instituições organizam e formalizam uma aprendizagem que já se iniciou na família e que terá continuidade nas experiências com a sociedade. Isto é, a família representa um elo forte que liga o sujeito ao mundo, mas ela, sozinha, não é responsável pela aprendizagem da vida social.

\section{Famílias negras e famílias inter-raciais: valores organizativos específicos}

No Brasil, os estudos sobre socialização em famílias negras e inter-raciais são lacunares. Havia pouco interesse ${ }^{5}$, até pouco tempo atrás, em realizar estudos sobre a especificidade dessas famílias. Neste contexto, contribuições importantes têm sido oferecidas $^{6}$ com o objetivo de aprofundar análises iniciadas e desafiar estudiosos a reavaliar os trabalhos disponíveis, ampliado a concepção integracionista sobre família.

Barbosa (1983), ao estudar a socialização em famílias negras na cidade de Campinas, verificou que os pais fornecem a seus filhos "elementos ambíguos no processo de socialização". Isto é, não há, por parte dos pais, uma orientação no que diz respeito ao enfrentamento das questões raciais e, por outro lado, as situações de racismo vivenciadas pelos filhos têm feito com que estes questionem os pais sobre a educação recebida.

Para a autora, no processo de socialização, não se pode esquecer do fato de que "todos os indivíduos que participam de uma vida social recebem, em menor ou maior grau, influências socializadoras, e por isso são mais ou menos ajustados aos padrões da sociedade em que vivem." A autora destaca esse aspecto com o intuito de enfatizar que tal processo é uma das funções mais importantes da família como um todo e, especialmente, da família negra. Barbosa salienta que a família negra,

\footnotetext{
${ }^{5}$ A partir dos anos de 1960, entre os estudos de caráter sociológico a respeito da história do negro, no período pós-abolição, destaca-se a obra de Florestan Fernandes, "A Integração do Negro na Sociedade de Classes" (1978). Segundo seu ponto de vista, no período pós-abolição, aos negros restou apenas conformar-se com a participação residual na economia de mercado, por meio de tarefas elementares e desprezadas socialmente. Ver também o artigo de "M.A" Helena P.T. Machado (1988).

${ }^{6}$ Ver os trabalhos: Brito (2002), Cavalleiro (1998), Cunha (1987), Silva (1987), Souza (1983), Souza (1999).
} 
Além de preparar as crianças para desempenhar os papéis exigidos pela sociedade, terá de prepará-las para desempenharem esses papéis em condições especiais, pois aqui a criança terá que saber ser uma criança negra vivendo entre brancos e negros numa sociedade preconceituosa e discriminadora (BARBOSA, 1983, p.51).

Mc Queen (1979 apud PACHECO, 1987) apresenta duas correntes que dividem os estudos sobre a família negra nos estados Unidos: os que defendem uma teoria adaptativa patológica da família negra e os adeptos de uma linha saudável. A autora aponta o trabalho de Florestan Fernandes, no Brasil, como contribuição para divulgação da linha patológica de adaptação. De acordo com a autora, para Fernandes (1978), a família negra, na cidade de São Paulo, durante as três primeiras décadas do século passado, poderia ser definida como uma família incompleta. O autor ressalta que seria impossível, na atualidade, determinar a frequência segundo a qual os vários arranjos estruturais se organizavam. Entretanto, parece fora de dúvida que o arranjo mais frequente consistia no par, composto por mãe solteira ou sua substituta eventual (quase sempre a avó) e seu(s) filho(s). Em segundo lugar, viriam os casais "amasiados", formados pelo par com o(s) filho(s) dos dois cônjuges (de sua união ou amasiados anteriores). Por fim, "os casais constituídos segundo os arranjos matrimoniais sancionados legalmente." (FERNANDES, 1978, p. 200).

Giacomini (1988) e Woortmann (1987) destacam a fragmentação da família africana como uma das consequências da escravidão. A incorporação da mulher negra ao ciclo reprodutivo da família branca inviabilizou, para os escravos, a constituição de seu próprio espaço reprodutivo. Assim, as relações eram precárias e efêmeras, ocorrendo, muitas vezes, à revelia dos próprios parceiros. Acabavam predominando os interesses dos senhores, mais preocupados em assegurar a reprodução de sua mão-de-obra. A legislação escravista enfatizava sempre a unidade "mãe-filhos", preocupando-se mais com a separação dos filhos em relação à mãe do que ao pai, desconsiderando também a separação entre os próprios cônjuges.

Nesse contexto, a mãe acaba assumindo sozinha a responsabilidade da prole, já que os parceiros estão sempre de passagem (GIACOMINI, 1988; WOORTMANN, 1987). Tratase, portanto, de uma família que apresenta certos valores organizativos específicos, porém, isso não quer dizer que o grupo rejeitasse, inteiramente, os padrões burgueses de família. 
Autores como Charles Ribeyrolles negam a existência da família cativa, apontando as consequências nefastas para o cotidiano e para a cultura das senzalas. Conceito este existente não apenas entre os viajantes europeus da época, mas, também, até há pouco tempo, entre os historiadores contemporâneos.

Entretanto, estudo realizado por Slenes (1994), em "A demografia e a economia da escravidão no Brasil: 1850-1888", trabalho importante e pioneiro, questiona a suposta ausência ou "patologia" da família escrava no Brasil, tão cara à historiografia brasileira dos anos 1960 e 1970 (FERNANDES, 1978). O estudo, de cunho demográfico, concluiu que a família conjugal escrava, apesar de sua vulnerabilidade face às condições da escravidão, "havia emergido como uma instituição social viável" nas regiões de plantation do Sudeste. Como consequência, "a família provavelmente ajudou muitos escravos a reterem sua identidade e lidarem efetivamente com as pressões psicológicas da escravidão." Ao mesmo tempo, "ao dar aos escravos um maior interesse na sociedade de plantation (isto é, algo significativo a perder) [...], a família também forneceu ao senhor um instrumento efetivo de controle social" (SLENES, 1994, p. 14).

O autor ressalta a contribuição da família negra tanto para a autonomia quanto para a dependência escrava, e argumenta que o escravismo não se baseava apenas na força, mas também numa política de incentivos "paternalistas", visando a dividir a comunidade escrava entre si. Dentre estes, destaca, especialmente, os incentivos à formação de famílias conjugais e à elaboração de estratégias para melhorar a sorte individual ou familiar, via mobilidade ocupacional e a alforria.

Uma pesquisa mais recente, de Pacheco (1987), afirma que muito pouco se avança na produção de estudos sobre a família negra brasileira. Para o autor, até mesmo a tese de Barbosa (1983), que tenta fugir do senso comum de relacionar a família negra a uma visão anômica, não traz maiores contribuições para essa discussão teórica. Ao optar pelo estudo de famílias negras, organizadas em seus processos de socialização da criança negra, reproduz e enfatiza a dicotomia entre famílias organizadas e desorganizadas.

Para Billingsley (1968 apud PACHECO, 1987), as famílias negras deveriam ser estudadas a partir delas mesmas, de suas estruturas e modos de funcionamento, e não 
tendo sempre como referência as famílias brancas, até por que, essas últimas, nem sempre foram constituídas nos moldes dos arranjos matrimoniais vistos como legais e corretos ${ }^{7}$.

Silva (1987) foi uma das primeiras pesquisadoras que buscaram apreender as famílias negras contemporâneas a partir delas mesmas, não tendo como referência famílias brancas. Em narrativas de suas experiências em uma comunidade de negros trabalhadores rurais em Limoeiro, desvenda o fato de como as pessoas que ali vivem se educam, vasculham, ordenam e reordenam suas vidas e a de sua comunidade, identificando motivos que se agruparem para formar a identidade e a socialização do grupo. Para a autora, a formação da identidade, na socialização desses negros, tem se dado através do trabalho dessas pessoas como empregados em uma fazenda. Tanto a identidade econômico-social (trabalhador) quanto a racial (negra) se apresentam como identidades de seres humanos oprimidos, que não têm manifestado, abertamente, atitudes que visam à reversão de tal situação. Para a autora:

\begin{abstract}
Embora rejeitem lembrar a época da sua história em que "negro era tratado que nem bicho", a memória do passado de escravatura está presente no dia-a-dia, nos gestos de subserviência, na dependência do patrão, na preferência pelo trabalho na granja, no trabalhar sem medida para os outros usufruírem e também nos rasgos do desejo de ser livre. Não falar da escravatura, talvez seja para os negros trabalhadores amaneira de aliviar a dor na ferida ainda aberta, e para os brancos, no caso os fazendeiros, um modo saudável de ignorar o quanto seus antepassados e eles ainda hoje estão implicados numa relação em que desumanizam outros seres humanos, desumanizando a si próprios (SILVA, 1988, p. 239).
\end{abstract}

A autora chama a atenção para o fato de que esses indivíduos constroem sua existência, apesar de pressionados pela condição de negros e trabalhadores rurais, e não se encontram passivamente sobrevivendo às circunstancias das suas vidas.

Em 1987, Henrique Cunha Junior ${ }^{8}$ realizou um estudo na cidade de São Carlos, por meio de visitas a famílias negras nos bairros, que assinala a dificuldade dos pais em

\footnotetext{
${ }^{7}$ Slenes (1994), ao tematizar o período escravista, mostra que havia um grande número de casamentos duradouros entre escravos, no Brasil; destaca a família enquanto uma instituição importante na organização da vida dos cativos, diferentemente do que era apontado, na historiografia sobre o tema, por autores como Gilberto Freyre, Emília Viotti $(1971,1966)$, Roger Bastide $(1971)$ e Florestan Fernandes (1964), que afirmavam que inexistia família na vida dos africanos e seus descendentes no país.

${ }^{8}$ No período de 1978 a 1981, organizou-se, na cidade de São Carlos, um grupo de estudos composto por membros do Centro Congada, de São Carlos, e do grupo Gana, de Araraquara, os quais se tornaram alunos regulares ou especiais dos cursos de pós graduação em educação da universidade Federal de São Carlos.
} 
decisões que envolvem informar os filhos sobre as questões referentes ao preconceito, à discriminação racial e ao racismo. O autor destaca, também, a preocupação que há, nessas famílias, em proteger seus filhos do sofrimento que ela, provavelmente, virá a ter que enfrentar ao entrar em contato com a sociedade mais ampla. Por outro lado, enfatiza que as reações dos pais frente às denúncias das crianças negras são: não acreditar nas crianças, pois pensam que tais coisas não existem na escola; duvidar que os fatos realmente ocorreram; a creditar que constituem um meio de os filhos resolverem outros problemas, como, por exemplo, não ir à escola ou mesmo buscarem atingir um professor de quem não gostam; e não dar importância ao fato. Os pais instruem as crianças quanto a dar respostas, mas ficam inseguros, reclamam na escola, mas duvidam do resultado obtido.

Mesmo existindo dificuldade em trabalhar e abordar questões ligadas à discriminação racial, não se pode dizer que não existe orientação por parte das famílias negras. O contexto revela que os pais se preocupam em educar, estão atentos aos processos discriminatórios e percebem as reações de seus filhos frente à discriminação racial. Muitas pesquisas têm disponibilizado contribuições positivas, que tentam aprofundar análises e reavaliar estudos disponíveis sobre a maneira de educar, de socializar-se na família negra.

Cavalleiro (1998), ao pesquisar a socialização de crianças em famílias negras de baixa renda, na região central de São Paulo, aponta que há socialização dos filhos para a vida social, mas estas não consideram o racismo, o preconceito e a discriminação que ainda imperam na sociedade. Ora, a ausência de estratégias, por parte das famílias, para o enfrentamento do problema das crianças, no espaço escolar, não sinaliza uma acomodação, mas, como já apontado anteriormente por Cunha (1987) e Barbosa (1983), uma estratégia para proteger a criança pequena de sofrimentos que, certamente, virão.

Em pesquisa realizada por Brito (1997), na cidade de Franca, interior de São Paulo, verificou-se que as famílias negras relatam não saber como lidar com a discriminação, mas, no cotidiano, enfrentam e orientam os filhos sobre questões relacionadas ao pertencimento racial. Os relatos revelam que, quando surge alguma atitude discriminatória, os pais, muitas vezes, vão ao local onde a agressão aconteceu e pedem explicação sobre o fato, o que significa dizer que há reação contra as atitudes 
discriminatórias. Logicamente, essa postura não acontece da mesma maneira em todas as famílias negras.

Por outro lado, Souza (1999), em sua tese "Os educadores e as relações interétnicas: mestres e pais", aponta que tanto a escola como a família não fornecem elementos para o desenvolvimento da identidade social e étnico-racial às crianças negras, e que, além disso, a família negra não orienta seus filhos para o fato "de que a $\operatorname{cor}^{9}$ de sua pele e outras características físicas e culturais irão influenciar suas relações sociais futuras". O autor identificou, também, que os pais tomam alguma providência em relação ao preconceito e à discriminação no momento em que aparece um problema específico. Por outro lado, os pais estimulam os filhos a estudarem para que consigam uma vida melhor. Por isso, Souza sublinha o fato de que o propósito das famílias negras não foge aos objetivos de qualquer família, ou seja, o de promover um contexto que possa suprir as necessidades primárias de seus membros, no que diz respeito a: sobrevivência, segurança, alimentação e um lar, o desenvolvimento afetivo, cognitivo e social e o sentimento de ser aceito em uma sociedade preconceituosa e racista.

\section{O papel das famílias no processo de construção da identidade racial: resistência, contestação e luta contra a discriminação e o preconceito racial}

Em todas essas pesquisas, reconheceu-se que a influência da família nas situações que envolvem discriminação racial é decisiva desde muito cedo. Como bem destacaram Cunha (1987), Brito (1998) e Cavalleiro (1998), quando os pais não dão importância aos

\footnotetext{
9 "Os povos europeus se definem e foram definidos como brancos, no contato com os outros, considerados negros, amarelos, vermelhos. Estamos diante de um discurso classificatório baseado em cores. Temos que dar tratos à bola para compreender este que é o mais naturalizado de todos os discursos. E quando falo naturalizado estou querendo dizer totalmente nativo, pois quanto mais nativo é um conceito mais ele é habitual, menos ele é exposto à critica, menos conseguimos pensar nele como uma categoria artificial, construída, mais ele parece ser um dado da natureza. É isso que quer dizer "naturalizado". Cor é um discurso desse tipo, uma categoria totalmente nativa; eu não posso falar muito dela, pois tenho que estudá-la mais um pouco. Eu poderia discorrer sobre raça; como surgiu a ideia de raça, os primeiros livros em que a palavra raça apareceu, qual o significado que tinha, etc.; existe uma enorme literatura sobre isso, mas sobre "cor" não existe. Na mais longínqua antiguidade, essa metáfora das cores já se aplicava à classificação dos seres humanos. "Cor" nunca é um conceito analítico, a não ser talvez na pintura, na estética, na fotografia; certamente na arte ele é um conceito analítico, mas nas ciências sociais ele é sempre nativo, usado para classificar pessoas nas mais diversas sociedades" (GUIMARÃES, 2003).
} 
fatos discriminatórios, os filhos podem manifestar desde insegurança, desconfiança e desprezo, até rebeldia, bloqueio, entre outros sentimentos.

Pode-se considerar, dentre as diversas formas de socialização praticadas por essas famílias, que há, em uma primeira análise, despreparo das mesmas diante do racismo, do preconceito e da discriminação racial. A dificuldade de falar sobre acontecimentos e situações que provocam mal-estar emocional dificulta o desenvolvimento de estratégias de ação para o enfrentamento do problema, pois as próprias famílias têm dificuldades para lidar e relatar episódios tão delicados. Entretanto, um retorno aos relatos evidencia que as famílias negras e inter-raciais, embora apresentem dificuldade e desconforto diante de um problema tão delicado, demonstram, também, atitudes de resistência e contestação como luta contra o preconceito e a discriminação racial.

Para compreender melhor como se processa a socialização nessas famílias, retomei e reli, inúmeras vezes, outra pesquisa realizada por mim, entre os anos de 1997 e 2000, na qual tentei desmontar os relatos e desvendar o que havia por trás do "despreparo" dessas famílias, o que permitiu concluir que as atitudes destas, mesmo com as dificuldades, não são tão ingênuas e despreparadas quanto parecem ou como meu olhar enviesado havia percebido. Em uma conversa entre mim e " $\mathrm{S}$ "10, negro de 34 anos, advogado formado na UNESP-Franca/SP, casado com uma mulher branca, com quem tem três filhos, "S" fala que o curso de direito na UNESP era considerado de elite, denotando que o próprio negro ${ }^{11}$, muitas vezes, está atento às discrepâncias raciais existentes na sociedade. "S" relata, ainda, que antes de se casar, sentou-se com sua esposa e conversou sobre o preconceito e a discriminação de que seus filhos seriam vítimas por serem filhos de um negro. Segundo ele:

Conversamos, conversamos muito principalmente por causa dos meus meninos, né?! Mesmo quando eu fui me casar com ela, fui falar com a família dela, eu expliquei para ela que nós não sabíamos como poderia sair os filhos. E... Até alertei que ela poderia ter problemas relacionados a isso. As pessoas poderiam criticar, poderiam perguntar... Embora nosso país dizem que é um país que não tem preconceito existe muito preconceito (S).

\footnotetext{
${ }^{10}$ Entrevista realizada em 1988, na cidade de Franca, interior de São Paulo, sob o financiamento da FAPESP.

${ }^{11}$ "S" filho de pai negro e mãe branca se identifica como negro.
} 
Quando os membros que compõem uma família não negam o racismo brasileiro, ou seja, como diz Cunha (1987), quando as crianças são preparadas em casa, têm mais facilidade para reagir frente aos efeitos da agressão; assim, os fatos são mais facilmente superados. Foi o que pude comprovar em trabalho anterior, (BRITO, 1998), ao entrevistar "G"12, ex- padre negro, considerado de classe média, na cidade de Franca. Na ocasião, fui informada de que o casal orientava suas filhas sobre o racismo e a discriminação racial. Ele descreveu, então, uma situação de discriminação vivenciada por sua filha em uma escola particular da cidade, cujo destaque é a reação da filha, que já tinha sido alertada pelos pais sobre os possíveis atos discriminatórios que sofreria por ser negra. Segundo o pai:

\begin{abstract}
Olha no dia que ela me contou, né. Que uma menina falou prá ela, que ela era preta. Ela me contou já contando prá mim que ela já tava, sabe eu achei interessante, ela não veio reclamar, ela veio me dizer que já estava acontecendo aquilo que eu esperava que acontecesse. Já tinha conversado sobre isso lá em casa, as meninas vão percebendo claramente isso, né, porque elas, porque eu assumo a minha negritude sabe. Hoje a cada dia eu assumo com mais tranquilidade, mais clareza. Então, esse fato, de elas perceberem que o pai assume que é negro, facilitou elas ter a consciência da realidade da discriminação. Quando tá acontecendo, no caso da Lídia, isso ocorreu uma vez só, então, mas a reação ela foi fantástica, ela viu, ela percebeu, e não precisou de eu explicar prá ela que existe a questão. Porque fez parte de um processo natural, tá. Naturalmente, e isso prá mim foi uma alegria muito grande. Não, ela não reagiu, ela ouviu e já captou tá certo? Ela já entendeu na hora e não discutiu com a pessoa. Porque é a inocência, né. Mas a Lídia eu percebi assim, que ela tem uma consciência muito forte disso (G).
\end{abstract}

Esse trabalho apresenta relatos de experiências positivas sobre a orientação das famílias acerca do racismo, do preconceito e da discriminação racial. Necessita-se, portanto, de outras pesquisas, que sejam sensíveis e aprofundem o tema, conferindo maior relevância ao assunto.

A reflexão sobre o processo de socialização em famílias negras e em famílias interraciais é muito incipiente no Brasil. Uma análise para sua compreensão se torna, pois,

\footnotetext{
${ }^{12} \mathrm{Em}$ 1998, pude realizar uma pesquisa com seis casais inter-raciais (negros e brancos). A pesquisa, que se intitulava: "Nem preto nem branco: a ideologia do branqueamento e o medo de ser negro numa sociedade de contrates", hoje me surpreende, pois o medo, fruto de minha ingenuidade e inexperiência, se transformou em coragem e luta. A maioria dessas famílias, embora relatassem que não sabiam como trabalhar a questão do racismo e da discriminação com seus filhos, revelaram que tinham estratégias para lidar com esse assunto tão delicado. BRITO (1998).
} 
indispensável, dada sua importância na constituição do ser. Conforme Gomes (1990, p. 60):

Ao final do processo de socialização a criança não só domina o mundo social circundante, como já incorporou os papéis sociais básicos - seus e de outros, presentes e futuros - mas, acima de tudo, já adquiriu as características fundamentais de sua personalidade e identidade.

No que diz respeito à socialização em famílias inter-raciais formadas por negros/as e branco/as, é necessário apreender: como os agentes envolvidos no processo de socialização (no caso, pai e mãe) transmitem questões referentes às diferenças étnicoraciais; como ocorre esse diálogo e quais os mecanismos que esses agentes utilizam para lutar contra o preconceito e a discriminação racial, de modo a identificar formas de lidar com os mesmos nos diferentes espaços institucionais; e como seria, enfim, a compreensão da criança sobre esses fatores. Como essas famílias preparam seus filhos para o pertencimento racial?

Em outro estudo realizado por mim em $2000^{13}$, aponto o relato de " $R$ " , 21 anos, estudante de direito na UNESP, filha de negro e branca. " $R$ " diz que sua mãe, que era negra, tinha uma visão crítica sobre o significado de ser negra e da maneira de como educar os filhos. Talvez, o fato de sua mãe ser negra e de ter vivenciado situações de discriminação, contribuiu para que tivesse uma postura crítica e contestadora diante de situações de preconceito e discriminação envolvendo seus filhos.

Com o intuito de responder algumas indagações que a pesquisa realizada em 2000 não conseguiu concluir, tento extrair das falas desses sujeitos (filho, mãe, pai) onde se dá a ruptura, a modificação, e como esses filhos foram construindo seu pertencimento racial, sua identidade, no contexto dessa mesma estrutura social que discrimina e silencia. Naturalmente, deve-se entender a socialização e a própria identidade como um processo dinâmico, que possibilita a (re)construção gradativa da personalidade no decorrer da existência do indivíduo.

O depoimento de "M.A" revela a forma como alguns professores têm tratado as crianças negras em sala de aula. A entrevistada recorda-se, com tristeza, de uma

\footnotetext{
${ }^{13}$ Este estudo abrangeu somente os sujeitos socializados filhos de relacionamento entre negros e brancos: mestiços. (BRITO, 2000).
} 
experiência vivenciada na infância, à qual dedico especial atenção, por considerar a gravidade e a repercussão que um acontecimento desse tipo tem na vida dos mestiços e dos negros. Dessa forma, apresento o seguinte relato,

\begin{abstract}
Então ela fazia uma trança tão apertada... Tão apertada que eu parecia japonesa, eu não esqueço uma vez que a gente foi, que ela trançou, ela trançava sempre a tarde, depois que a gente tomava banho. Aí eu não sei se era umas duas vezes por semana e ficava e eu morria de vergonha, então eu só usava lencinho por cima, porque os meninos da escola me chamavam de "M.A" trancinha, então eu usava lencinho. E uma das vezes ela trançou mais doeu tanto, tanto que eu fui dormir e desmanchei tudo a noite. No outro dia eu já acordei meio atrasada para ir para escola, eu estava na $3^{3}$ série, era dia de tirar fotografia, uma fotografia com beca, com não sei. Nossa eu acho que foi o dia mais triste da minha vida. [...] Ai tive que tirar com beca né, aí a hora que eu cheguei a hora que foi a minha vez, "ai meu Deus..." [...] Eu já estava pensando e fila, e a criançada tirava sarro que eu era pretinha, assim eu era triste. Aí veio a professora e falou: "Você não vai querer ficar com esse lenço né?" E tirou meu lenço, hora que tirou, ai as trancinhas que tinha sido desmanchadas estavam assim uma medusa mais ou menos. Ah mas a meninada ria tanto e eu fui ficando tão sem graça, tão magoada que comecei a chorar ai eu tirei a foto chorando, tudo de azul, aquele um azul Royal, sabe aquela cor? Pesquisadora: Eu sei.

"Aí os meninos, os meninos riam cada vez mais, quanto mais eu chorava, ai quando veio a foto era Divinópolis, ainda naquele tempo, Divinópolis. Ai aquele reflexo do azul da beca, das minhas lágrimas, meu olho ficou azul e minha mãe achava lindo que ela era devota de nossa senhora, ela falava assim: "nossa, mas ficou parecendo nossa senhora"! Eu com aquela cara de velório, que tristeza sabe, nossa eu acho que eu nunca passei tão mal em minha vida.

Pesquisadora: E você tem a foto até hoje?

"Ah eu não tenho, eu joguei. Sabe o que aconteceu, todo mundo que chegava lá em casa minha mãe ia mostrar essa foto, eu tinha tanta raiva da professora ter tirado meu lenço lá no meio dos outros que eu me senti nua, com aquilo lá. Nossa até quando eu vim para Franca eu ainda usava lenço ainda, aqui em Franca que eu parei com isso, a gente fica com complexo, as orelhas ficava até pregada. Aí então eu joguei a foto fora (M.A).
\end{abstract}

Esse depoimento é utilizado como forma de denúncia, algo que deve ser lido por todos aqueles que lutam para construir um país cujas diferenças sejam respeitadas!

$\mathrm{Na}$ verdade, a experiência de "M.A" é apenas uma dentre tantas outras que ocorrem, cotidianamente, em escolas, em salas de aula de todo o Brasil. No depoimento de "M.A", a professora branca "mutila" a aluna, expõe sua negritude, torna isso um fato público; enfim, põe-se à vontade para interferir no corpo que é também a alma da aluna, o que contribui para a cristalização de uma visão, segundo a qual, as características dos mestiços e negros são mostradas de forma degradante e vergonhosa. A professora ridiculariza "M.A" ao the retirar o lenço, além de agredi-la fisicamente, quando puxa o 
lenço de sua cabeça sem Ihe pedir licença. Assim, a professora deixa de respeitar a vontade de "M.A" de permanecer com o lenço e não impede que os alunos e alunas brancos e brancos a ridicularizem.

A professora expõe a aluna a uma situação que, para esta, pode ser comparada à morte: "eu com aquela cara de velório". A professora branca "mata", simbolicamente, "M.A", quando retira o lenço de sua cabeça e a expõe aos comentários dos alunos brancos. Entretanto, "M.A" vive tal situação e defende-se dela quando a verbaliza na entrevista: "eu tinha tanta raiva da professora". Assim, "M.A" não esconde o ódio que sente da professora, por esta tê-la agredido e por não respeitar sua vontade. E esse ódio é concretizado no instante em que "M.A" se desfaz da fotografia, um ato que simboliza a reação de "M.A" perante a situação de humilhação. Chorar, permanecer quieta, num primeiro momento, não significou ausência de reação ao fato. Pode ter, inicialmente, expressado o silêncio, mas o silêncio é uma estratégia de resistência que, embora frágil, às vezes, não deixa de ser estratégia; o silêncio é uma arma.

Um olhar atento para a escola pode captar situações que se configuram, de modo expressivo, como atitudes racistas. De forma objetiva ou subjetiva, a educação apresenta preocupações que vão do material didático-pedagógico à formação de professores.

Essa prática discriminatória ${ }^{14}$ evidencia que nem mesmo os conhecimentos valorizados pela família são considerados, reconhecidos e compreendidos pela escola. A professora desconsidera os valores e os conhecimentos da aluna, pois o lenço, para "M.A", não somente tinha uma representação simbólica como também uma história familiar: a avó usava lenço, a mãe usava lenço, portanto, "M.A" usava lenço. A professora desrespeitou a história de vida de "M.A" e, diante disso, a pergunta formulada é a seguinte: Caso fosse uma aluna branca, a professora branca teria procedido da mesma maneira?

À medida que a criança aumenta seu contato social fora da família, isto é, quanto mais se insere em outros círculos que não o da família, mais percebe a tensão entre negros

\footnotetext{
${ }^{14}$ A publicação da Lei Caó, no 7.716/89 define os crimes resultantes de discriminação por raça ou cor no campo educacional. A Lei 10.639/2003, que altera a Lei de Diretrizes e Bases da Educação, inclui, no currículo oficial, a obrigatoriedade da temática "História e Cultura afro-brasileira", o que assinala as intenções, por parte do Estado brasileiro, de eliminar o racismo e a discriminação racial.
} 
e brancos. Obviamente, os filhos de negro e branco ${ }^{15}$ não deixam de ser discriminados, ou a discriminação é mais amena, por possuírem características fenotípicas do branco; antes, o que há, é um escamoteamento maior das manifestações de discriminação em relação aos mesmos.

Muitas vezes, as práticas educativas, que se pretendem iguais para todos, acabam sendo as mais discriminatórias. "Essa afirmação pode parecer paradoxal, mas dependendo do discurso e da prática desenvolvida, pode-se incorrer no erro da homogeneização em detrimento do reconhecimento das diferenças" (GOMES, 2001, p. 86). Por este motivo, buscou-se localizar o conceito e o processo de educação no contexto das coletividades e das pessoas negras e a relação destas com os espaços sociais. É imprescindível o debate da educação a serviço da diversidade, tendo como desafio a afirmação e a revitalização da autoimagem dos afrodescendentes.

\section{"Lares negros, olhares brancos": a homogeneização dos estudos sobre socialização em famílias numa perspectiva compulsória a todas as raças}

O Serviço Social tem sido referência nos debates relativos à família. Muito se tem produzido e discutido sobre o aludido tema, em relação a seu histórico, sua importância, suas formas de socialização e sobre as metodologias para melhor se trabalhar com esta realidade. São raras as produções que tratam das especificidades das famílias negras e inter-raciais, no âmbito do Serviço Social, embora se tenha consciência de que a questão racial é dissimulada e camuflada. É importante destacar que o negro está ausente ou excluído em vários aspectos sociais. Os assistentes sociais, quando falam em pobreza, desemprego, exploração, falta de moradia, identidade, concentração de renda, saúde, violência, família, idoso, trabalho infantil e outros assuntos relacionados à exclusão social, não identificam os protagonistas dessa tragédia tendo como referencial a origem racial das pessoas envolvidas, ou seja, não realizam o recorte racial. É como se não quisessem encarar o assunto, e silenciar. Elimina-se o problema não o enfrentando. Não se toca no assunto,

\footnotetext{
15 Os sujeitos entrevistados, que sofreram e ainda sofrem discriminação, são pessoas da classe média: professores universitários (ex-padre), advogado, gerente do banco do Brasil, somente "M.A" que no momento da entrevista, era empregada doméstica.
} 
não se discute nem se aprofunda. Não se dá "cor" ao contingente mais atingido pela desigualdade.

A invisibilidade da questão racial pode ser interpretada como um fato que não se nota, nem se discute. A temática debatida é vista do ponto de vista eurocêntrico e branco ${ }^{16}$. Os fatos são representados por todos, na sociedade, como se houvesse uma preponderância absoluta, uma supremacia definitiva de brancos sobre negros. A questão é: Por que não há recorte racial na maioria das pesquisas publicadas pelo Assistente Social?

O silêncio sobre as dinâmicas das relações raciais tem permitido que seja transmitida aos(s) alunos(as) uma pretensa superioridade branca, sem que haja questionamentos, por parte dos(as) profissionais, sobre práticas cotidianas prejudiciais ao grupo negro. Silenciarse diante do problema não apaga, magicamente, as diferenças, ao contrário, permite que cada um construa, a seu modo, um entendimento, muitas vezes, estereotipado do outro, do diferente. Esse entendimento acaba sendo pautado pelas vivencias socia is de modo acrítico, conformando a divisão e as hierarquizações raciais.

Este estudo tem como destaque as famílias negras e inter-raciais e a temática racial da população negra - o contingente formado por brasileiros identificados como pretos e pardos, pelos censos da Fundação IBGE.

Não há dúvida de que os profissionais reconhecem a desigualdade, mas é preciso destacar que esta também é fruto da discriminação racial historicamente produzida. 0 racismo está tão profundamente arraigado no tecido social e na cultura da sociedade que todo repensar da cidadania precisa incorporar desafios sistemáticos contra a prática do racismo. Seria importante considerar que o mito da democracia racial também permeia os cursos e a produção intelectual? Somos todos iguais? Nesse sentido, é importante destacar a importância da participação crítica do assistente social no trato das questões ligadas à diversidade étnico-racial.

O Código de Ética Profissional (CONSELHO FEDERAL DE SERVIÇO SOCIAL, 1993) determina que é dever do profissional empenhar-se na eliminação de todas as formas de preconceito, incentivando o respeito à diversidade, a participação de grupos socialmente discriminados e discussões sobre as diferenças. Assim, enfatiza-se a importância da

\footnotetext{
${ }^{16}$ Na revista Serviço Social \& Sociedade, uma das mais importantes revista de circulação da categoria, a temática racial aparece apenas em 3 (três) exemplares: Ribeiro(2004), Amaro (2005) e Rocha(2009).
} 
intervenção como forma de prevenir e superar as relações discriminatórias que surgem em todas as esferas sociais (BRITO; LOPES, 2010).

Góis (2006) observa que, embora exista uma agenda de investigações com importantes temáticas, tais como, a democracia, os direitos sociais, o bem-estar social etc, a sociedade ainda é marcada por características reducionistas. Para o autor:

O modo como essa agenda se constituiu, contudo marcado por algumas características forte reducionismo intelectual, generalizações teóricometodológicos, a-historicismo, etc - que inibiram o desenvolvimento intelectual da profissão. Além das características já mencionadas vale destacar supostamente distantes da esfera das contradições entre capital e trabalho e do confronto entre Estado e Sociedade. Assim questões tidas como muito subjetivas ou particularistas- a exemplo dos debates sobre gênero e raça foram tanto negligenciadas quanto consideradas "conservadoras" ou, principalmente a partir dos anos de 1990, tomadas pejorativamente como pós-modernas (GÓIS, 2006, p. 9-13).

O debate sobre gênero, mesmo marginalizado, consegue "entrar" na pauta do Serviço Social, mas a discussão sobre raça continua sendo preterida na agenda intelectual da profissão. Paralelamente, Lisboa (2010) aponta para a desconsideração sobre estudos pertinentes ao gênero e à raça, em Serviço Social.

\begin{abstract}
A partir dos anos 1960, ocorre no Brasil e na América Latina o Movimento de Reconceitualização do Serviço Social. Este movimento teve um importante papel na medida em que pretendeu romper com as teorias importadas e trabalhar na realidade do povo brasileiro. Porém, ao incorporar a teoria marxiana, a profissão sofreu a imposição de uma tendência homogeneizadora de construção do pensamento social, de uma teoria que se pretende universal e prioriza o enfoque de classe, desconsiderando a heterogeneidade do pensamento a partir das dimensões sócio-históricas e culturais que emergem no cotidiano das práticas, entre elas as diferenças sexuais, de identidade, de raça/etnia e de gênero (LISBOA, 2010).
\end{abstract}

Ao discutir a construção do conhecimento, a autora argumenta que, ao longo da história, as sociedades andaram em descompasso em relação aos estudos feministas e/ou estudos de gênero e de raça, "e que esse desencontro contribuiu para consolidar um estatuto acadêmico e uma administração do saber que reproduz a questão de gênero e legitima a dominação masculina" (LISBOA, 2010, p.2). Este desencontro colaborou também para a ratificação e a reprodução de discursos preconceituosos e etnocêntricos, baseados na supremacia racial do branco, na ideologia do branqueamento e no mito da falsa democracia racial no país (BRITO, 2013). 
Assim, tratando-se de profissionais que lidam, cotidianamente, com as refrações da questão social e, portanto, historicamente, com a população empobrecida, ou seja, os afrodescendentes, o domínio de conhecimentos sobre a história, a cultura afro-brasileira e as questões concernentes às relações raciais, no Brasil, é habilidade fundamental para se combater as diferentes formas de dominação. Desse modo, constitui um instrumento contra o preconceito e a discriminação, importante "para um melhor aprimoramento pessoal como para um desempenho profissional mais consciente e crítico de intervenção diante da realidade social e econômica do público que busca seus serviços." (BRITO, 2013).

\section{Considerações finais}

O entendimento da cultura enquanto linguagem e mesmo enquanto prática filosófica cotidiana traz o reconhecimento de novos espaços para a construção e a aplicação de metodologias especificas, que não as já estabelecidos pelas instituições, cujo caráter ideológico de dominação não mais responde às novas demandas populares. Fazse necessário, pois, um reposicionamento e, mesmo, uma redefinição dessa prática social, com base em novas visões de realidade.

É preciso questionar os seguintes aspectos: Quais metodologias devem ser utilizadas no trabalho com famílias negras e inter-raciais? E com as crianças negras vítimas de preconceito nas escolas e em outros ambientes institucionais? Como trabalhar com moradores de comunidades quilombolas? E de favelas? E no campo da saúde? Como há doenças que acometem, especificamente, a população afrodescendente, como os assistentes sociais devem lidar com esta situação? (SANTOS, 2011). Quais as relações sócioraciais e de gênero que permeiam os locais do trabalho (HALSENBALG, 2005.) e outros ambientes institucionais? Os homossexuais negros, de que forma são tratados? E os moradores de rua, quem são? Onde moram os negros? Em que tipos de residência vivem? (BRITO, 2013).

Há diferentes modos de atuar com sujeitos que são diferentes, não se pode homogeneizá-los como se todos fossem brancos, pois as especificidades de cada grupo social devem ser consideradas. A história de vida, assim como, a trajetória de vida dos negros, de forma alguma, é igual a dos brancos, mesmo dos brancos pobres. A contextualização deve ser mediada pelas diferentes concepções teóricas que perpassam as 
questões de classe, de gênero, de raça/etnia, que se baseiam em múltiplos tipos de saberes. Segundo Falleiros:

\begin{abstract}
Especificamente no Serviço Social estas questões também se apresentam, apesar da vitalidade do marxismo, como corrente teórica de análise e compreensão da realidade, e da manutenção da hegemonia do projeto profissional assinalado pela ruptura com o conservadorismo que caracterizou a trajetória do Serviço Social no país. Colocam-se novos desdobramentos e nas polêmicas em torno dos modelos clássicos e na busca de construção de novos paradigmas; se colocam pela apropriação do pensamento de autores contemporâneos de diversas tendências teórico-metodológicas como Anthony Giddens, Hannah Arendt, Pierre Bourdieu, Michel Hobsbawm, E.P. Thompson e tantos outros. Se constituem também nas formas de abordagem das temáticas relevantes para a profissão nesta transição de milênio, na busca de interligação entre sujeito e estrutura e entre concepções macro e micro da vida social, na retomada e valorização das questões concernentes à cultura das classes subalternas e em outras clivagens e questões relativas aos dominados tanto no plano das relações culturais como nas lutas pelo empowerment e contra a discriminação pelo gênero, pela etnia, pela idade (FALLEIROS, 1996 apud YASBEK, 2009, p. 158).
\end{abstract}

Para autora, no campo da produção inspirada na tradição marxista, estas questões podem ser discutidas a partir de pensadores que abordam temáticas da cultura das classes subalternas, do sujeito e da experiência cotidiana da classe, como Gramsci, Heller e Thompson.

Os estudos sobre raça abrem possibilidades para se refletir sobre outra forma de pensar a condição histórica de negros e afrodescendentes, sobretudo, sobre as desigualdades raciais. Neste contexto, pode-se levantar a seguinte questão: Até que ponto o mito da democracia racial permeia o interior da profissão em estudo, no que diz respeito à invisibilidade dos negros nas Diretrizes Curriculares que direcionam os cursos de Serviço Social no país? Além disso, é fundamental refletir sobre que tipo de formação tem sido propiciado aos futuros assistentes sociais (SILVA FILHO, 2006). Como pondera Rocha (2009), não tem sido relevante, nas reflexões realizadas na formação profissional do Assistente Social, o debate sobre o racismo como mecanismo de discriminação e desigualdades. Dessa forma, é preciso considerar que,

A articulação das categorias de raça/etnia, classe e gênero para a compreensão das relações sociais e dos seus determinantes constitui fator fundamental para a intervenção profissional, haja vista as demandas sociais de origens diversas que se colocam como desafio no cotidiano do trabalho do assistente social (ROCHA, 2009). 
É evidente a persistente e crescente carga de pobreza que recai sobre os negros e afrodescendentes no Brasil, pois estes constituem os principais usuários dos Programas de Assistência Social. Como, no Brasil, historicamente, os negros são os mais pobres e representam grande parte das pessoas atendidas pelos assistentes sociais, era de se esperar que as entidades representativas da categoria disponibilizassem de um conjunto de estratégias e ações voltadas, diretamente, para esse segmento populacional e que assumissem, de forma mais decisiva, esse assunto e essa discussão. ${ }^{17}$

É imprescindível reconhecer e combater o preconceito e a discriminação racial no cotidiano profissional. Faz-se necessário apreender, criticamente, o processo histórico dos afrodescendentes para promover o respeito mútuo, o respeito ao outro, o reconhecimento das diferenças e a possibilidade de se falar sobre as diferenças sem medo, receio ou preconceito. É preciso trabalhar de modo que a sociedade brasileira se torne um espaço público em que haja igualdade de tratamento e oportunidades.

\section{Referências}

AMARO, S. A questão racial na assistência social: um debate emergente. Serviço Social e Sociedade, São Paulo, n. 81, p. 58-81, 2005.

BARBOSA, I. M. F. Socialização e identidade racial. Cadernos de Pesquisa, São Paulo, n.63, p. 54-55, 1987.

. Socialização e relações raciais: um estudo de família negras em Campinas. São Paulo: FFLCH/USP, 1983.

BERGER, P. L.; LUCKMANN T. A construção social da realidade. 3. ed. Petrópolis: Vozes, 1976.

BLOOM, L. Psicología social de Las relaciones de raza. Bueno Aires: Granica, 1974.

BRITO, A. E. C de. A atuação dos educadores na formação da identidade da criança negra na escola. Franca: PIBIC/CNPq/UNESP, 1997.

${ }^{17} \mathrm{O}$ Conselho Federal, em parceria com entidades da sociedade civil e universidades, lançou uma campanha Nacional de Combate ao racismo. Consideramos esta uma iniciativa ainda focalizada, isolada, que pulveriza ações mais concretas. Embora importante, precisamos de mais iniciativas que sejam constantes e permanentes. 
. Família inter-étnica e a escola: agentes socializadores ou tradição dos oprimidos? São Paulo, 2002. Relatório de pesquisa. II Concurso Negro e Educação.

Famílias interétnicas e a educação informal dos mestiços: perspectivas e dificuldades. São Paulo: Fundação Ford, 2000. Relatório de pesquisa: I Concurso negro e educação.

.Nem preto nem branco: a ideologia do branqueamento e o medo de ser negro numa sociedade de contrastes. 1998. Monografia (Especialista) - UNESP, Franca. 1998.

. Ontem eterno? Moradia e desigualdade sociorracial no Brasil, desafio para o Serviço Social. In: SIMPÓSIO MINEIRO DE ASSISTENTES SOCIAIS, 3., 2013, Belo Horizonte. Expressões Sócio-Culturais da crise do capital e as implicações para garantia dos direitos sociais e para o serviço social. Belo Horizonte, 2013.

BRITO, A. E. C.; LOPES, J. C. Desigualdades raciais no Brasil e suas repercussões no processo de formação das crianças negras: uma reflexão sobre o papel da instituição escolar e sobre o serviço social no enfrentamento da questão racial. In: MOSTRE SEU VALOR - PNUD. Recife, 2010. (Série textos de apoio ao RDH 2009/2010).

CAVALLEIRO, E. S. Do silêncio do lar ao silêncio escolar: racismo preconceito e discriminação racial na educação infantil. 1998. Dissertação (Mestrado em Educação) Faculdade de Educação da Universidade de São Paulo, São Paulo. 1998.

CONSELHO FEDERAL DE SERVIÇO SOCIAL - CFESS. Código de ética profissional dos assistentes sociais. Brasília: CFESS, 1993.

CUNHA, H. A indecisão dos pais face a percepção da discriminação racial na escola pela criança. Cadernos de Pesquisa, São Paulo, n. 63, p. 51-53, nov. 1987.

ERIKSON, E. H. Identidade, juventude e crise. Rio de Janeiro: Zahar, 1976.

FALEIROS, Vicente de Paula. Serviço Social: questões presentes para o futuro. Serviço Social e Sociedade, São Paulo, n. 50, p. 9-36, 1996.

FERNANDES, F. A integração do negro na sociedade de classes. São Paulo: Ática, 1978. 2 V.

. O negro no mundo dos brancos. São Paulo: Difusão Européia do livro, 1972.

FREIRE, G. Casa Grande e Senzala: formação da família brasileira sob o regime de economia patriarcal. 19. ed. Rio de Janeiro: José Olympio, 1978.

GIACOMINI, S. Mulher e escrava. Rio de Janeiro: Vozes, 1988.

GÓIS, J. B. H. Apresentação. In: SILVA JUNIOR, Jose B. O serviço social e a questão dos negros na sociedade brasileira. Rio de Janeiro: Marques Silveira, 2006. p. 9-13. 
GOMES, J. V. Socialização primária: tarefa familiar? Caderno de Pesquisa, São Paulo, n. 91, p. 54-61, nov. 1994.

. Socialização: um estudo com famílias de imigrantes em bairro periférico de São Paulo. 1987. Tese (Doutorado em Psicologia) - Instituto de Psicologia da Universidade de São Paulo, São Paulo. 1987.

Socialização: um problema de mediação? Psicologia/USP, São Paulo, v.1, n. 1, p.57-65, jan/jun. 1990.

GOMES, N. L. Educação cidadã, etnia e raça: o trato pedagógico da diversidade. In:

CAVALLERO, E. Racismo e anti-racismo na educação: repensando nossa escola. São Paulo: Summus, 2001. p. 83-96

GUIMARÃES, A. S. Como trabalhar com "raça" em sociologia. Educação e Pesquisa, São Paulo, v. 29, n.1, p. 93-107, jan./jun. 2003.

Racismo e anti-racismo no Brasil. São Paulo: Fundação de Apoio à Pesquisa da Universidade de São Paulo: Ed.34, 1999.

HALSENBALG, C. A. Miscigenação racial no Brasil. Estudos Afro-Asiáticos, Rio de Janeiro, n. 16, p. 167, 1997.

2005.

. Discriminação e desigualdades raciais no Brasil. 2. ed. Belo Horizonte: Ed. UFMG,

HOFBAUER, A. Uma história de branqueamento ou o negro em questão. 1999. Tese (Doutorado em História) - Departamento de Antropologia, FFLCH/USP, São Paulo. 1999.

LISBOA, T. K. Gênero, feminismo e serviço social: encontros e desencontros ao longo da história da profissão. Revista katálysis, Florianópolis, v. 13, n. 1, p. 66-75, jan./jun. 2010.

MACHADO, M. H. P. T. Em torno da autonomia escrava: uma nova direção para a história social da escravidão. Revista Brasileira de História, São Paulo, v. 8, n. 16, p. 143-160, ago. 1988.

MOURA, C. O negro, de bom escravo a mau cidadão? Rio de Janeiro: Conquista, 1977.

MUNANGA, K. Rediscutido a mestiçagem no Brasil: identidade nacional versus identidade negra. Petrópolis: Vozes, 1999.

PACHECO, M. D. P. T. A família negra algumas questões. Estudos Afro-Asiáticos, Rio de Janeiro, n. 13. 1987.

RIBEIRO, M. As abordagens étnico-raciais no Serviço Social. Serviço Social e Sociedade, São Paulo, n. 79, p. 148-161, 2004. 
RIBEYROLLES, C. Brasil pittoresco: história-descrições-viagens-instituições-colonização. Belo Horizonte: Itatiaia; São Paulo: EDUSP, 1980. v. 2.

ROCHA. R. F. A questão étnico-racial no processo de formação em serviço social. Serviço Social \& Sociedade, São Paulo, n. 99, p. 540-561, jul./set. 2009.

SANTOS, E. Racismo institucional desafio a igualdade racial: uma análise acerca do atendimento a população negra no Hospital Universitário Clemente de Faria - UFCF. 2011. Monografia (Graduação em Serviço Social) - Departamento de Ciências Sociais Aplicadas, Montes Claros. 2011.

SILVA FILHO, J. B. Apresentação. . O serviço social e a questão dos negros na sociedade brasileira. Rio de Janeiro: Marques Silveira, 2006.

SILVA, P. B. G. Diálogo pluri-cultural em escolas de 10 grau e formação de professores; contribuições da universidade e do movimento negro: relatório de pesquisa. São Carlos: UFSCar, 1994.

SILVA, P. B. G. Educação e identidade dos negros trabalhadores rurais do limoeiro. 1987. Tese (Doutorado em Educação) - FACED/UFRGS, Porto Alegre. 1987.

. Espaços para educação das relações interétnicas: contribuições da produção científica e da prática docente, entre gaúchos, sobre negro e educação. In: SILVA, L. H. (Org.). A escola cidadã no contexto da globalização. Petrópolis: Vozes, 1998.

SLENES, R. W. Lares negros olhares brancos: histórias da família escrava no séc. XIX. Revista Brasileira de História, São Paulo, v.8, n. 16, p. 189-203, 1988.

SLENES, R. W. Na senzala, uma flor: esperanças e recordações na formação da família escrava, Brasil Sudeste, século XIX. Rio de Janeiro: Nova Fronteira, 1994.

SOUZA, I. S. Os educadores e as relações inter-étnicas: mestres e pais. 1999. Tese (Livre Docência) - Faculdade de História e Serviço Social, UNESP. 1999.

SOUZA, N. S. Tornar-se negro: as vicissitudes da identidade do negro brasileiro em ascensão. Rio de Janeiro: Graal, 1983.

SZYMANSKI, H. Teorias e "teorias" de famílias. In: CARVALHO, Maria do Carmo Brant de. (Org.). A família Contemporânea em debate. São Paulo: EDUC; Cortez, 2001. p. 23-29.

WOORTMANN, K. A família das mulheres. Rio de Janeiro: Tempo Brasileiro, 1987.

YAZBEK, M. C. Os fundamentos históricos e teórico-metodológicos do serviço social brasileiro na contemporaneidade. In: ABEPSS. Serviço Social: Direitos sociais e competências. Brasília: 2009. p. 143-164. 
Recebido em: 19/05/2013 Aprovado em: 21/06/2013 